\title{
Drama social: notas sobre um tema de Victor Turner
}

\author{
Maria Laura Viveiros de Castro Cavalcanti
}

resumo $\mathrm{O}$ texto analisa a noção de drama social desenvolvida por Victor Turner em Cisma e continuidade em uma sociedade africana, seguindo a sugestão de Clifford Geertz sobre o referencial dramatúrgico utilizado na formulação dessa sugestiva metáfora conceitual. Trata-se de apreciar a eficácia dos recursos ficcionais utilizados pelo autor em sua escrita etnográfica no contexto do solo conceitual estrutural-funcionalista. A partir das narrativas dos dramas $N$ dembu, Turner coloca o leitor na posição de um espectador teatral. Seguindo o desenrolar das açôes dos personagens-chave dos dramas, assistimos ao desenrolar de uma trama que corresponde a um futuro sociológico imaginado, visto como inevitável: a fissura da unidade da aldeia $N d e m b u$.

palavras-chave Victor Turner. Drama social. Metáfora conceitual. Ilusão dramática. Etnografia.

A antropologia de Victor Turner (19201983) traz consigo o gosto pela "sujeiçấo ao vivido", para usar uma expressão de Claude Lévi-Strauss (1976). Porém, com Turner, a suposta sujeição transforma-se em um comprazerse com o vivido, em uma espécie de redenção pela imersão na experiência vital de um agora pleno de tensôes e desdobramentos futuros, coletivamente experimentado. Uma antropologia encharcada de finitude, de impossibilidades e contradiçóes, de profunda empatia pelo sofrimento humano (communitas e ritos de afliçáo).

A obra de Turner é tấo vasta quanto multifacetada, e nela há certamente muito a explorar ${ }^{1}$.

1. Apesar do marcante diálogo da antropologia brasileira com Victor Turner, (DaMatta, 1979; Leolpoli, 1978; Maggie, 2001; Turner, 1987; Vogel, Mello e Barros, 1998), apenas dois de seus livros encontram-se traduzidos para o português: $O$ processo ritual (Petrópolis:
Na bibliografia crítica disponível, Adam Kuper (1973) vê muito pouco de inovação na primeira fase da carreira intelectual de Victor Turner, e chega a dizer sobre o seu livro de estréia, Cisma e continuidade (Turner, 1996 [1957]) que:

Embora se possa afirmar com justiça que a análise de Turner não era teoricamente inovadora, como viriam a ser seus estudos do ritual Ndembu, a qualidade do material coletado e o esmêro com que foi apresentado e analisado colocam a monografia numa classe à parte (Kuper, 1973, p. 181).

Turner é freqüentemente saudado pelos estudos de símbolos e rituais que logo se seguiriam, como na avaliação de G. Lenclud, responsável pelo verbete sobre o autor no Dictionnaire de l'Ethnologie et de l'Anthropologie (Bonte; Pierre et Izard; Michel, 1991, p. 221):

Para além da riqueza excepcional dos materiais etnográficos apresentados à análise, a originalidade da contribuição de Turner para o conhecimento do fenômeno ritual e da atividade simbólica deve-se ao fato de sua obra conjugar pontos de vista geralmente mantidos separados na antropologia ${ }^{2}$.

Em re-interpretaçáo do simbolismo das árvores entre os Ndembu, Peirano (1993) também apontou o deslocamento conceitual empreendido por Turner rumo à co-extensão do sistema social com o de crenças e práticas,

Vozes, 1974) e, mais recentemente, Floresta de simbolos: aspectos do ritual Ndembu (Niterói: UFF, 2005 [1967]).

2. Tradução minha. 
que produziria as densas análises dos símbolos rituais $N d e m b u$.

As contribuições à antropologia das religióes de Turner, por sua vez, têm sido unanimemente reconhecidas (Deflem, 1991; De Boeck; Devish, 1994; Weber, 1995). Também o são seus estudos sobre performance, atualmente tão em voga, que dialogam sobretudo com a fase final de sua carreira - From ritual to theatre (1982) e com dois livros póstumos Anthropology of experience (1986) e Anthropology of performance $(1987)^{3}$.

No conjunto de sua obra, é possível distinguir um núcleo "duro" de "antropologia clássica”, isto é, de uma antropologia que se movimenta, explora e testa limites no solo conceitual do estrutural-funcionalismo, a chamada antropologia social britânica. Esse núcleo abarca o conjunto dos livros escritos sobre os $N d e m b u$ e sua atividade ritual, que vão, grosso modo, de 1957, com a publicação de Cisma e continuidade, a 1968, com o lançamento de The Drums of affliction. Nessa perspectiva, $O$ processo ritual (1974 [1969]), ao desenvolver o conceito de communitas a partir da noção clássica de liminaridade (Van Gennep, 1960 [1909]), pode ser visto como um livro de passagem para uma nova etapa da obra de Turner. Nela, a etnografia dos Ndembu passaria a dialogar com os mais diversos fenômenos das chamadas sociedades ocidentais - dos movimentos milenaristas às comunidades hippies e finalmente desembocaria nas idéias de uma antropologia da performance e da experiência (Dawsey, 2005).

Este artigo se atém a um aspecto da fase inicial da carreira de Turner e procura realçar a originalidade e a inquietação já presentes em

3. Rubens Alves da Silva (2005) examinou a noção de drama em Turner enfatizando suas conexôes com o tema da liminaridade e da performance. Para as conexôes entre os temas do drama e da performance e da experiência, ver também Dawsey (2006).
Cisma e continuidade em uma sociedade africana $(1996 \text { [1957] })^{4}$, monografia baseada na pesquisa de campo realizada em dois períodos: entre dezembro de 1950 e fevereiro de 1952, e entre maio de 1953 e junho de 1954.

Com esse livro de estréia, Turner formulou com sucesso a noção de drama social, introduzindo uma instigante heterodoxia nas análises funcionalistas dos processos de conflito entáo em voga. Clifford Geertz (1997) já chamou a atenção para o uso da metáfora conceitual do drama por Turner. James Clifford (1998), por sua vez, renovou a leitura antropológica das etnografias clássicas, ao propor o exame dos diferentes registros internos à construção de suas narrativas. A análise proposta toma essas sugestôes como ponto de partida.

\section{O conceito de drama social em Cisma e continuidade}

No prefácio à segunda edição de Cisma e continuidade, datado de 1968, Turner (1996) afirma que os dramas sociais pretendem ligar a compreensão do processo social à estrutura social, em formulaçôes cheias de ortodoxia e do vocabulário teórico da época. Dramas sociais são definidos como:

uma sucessão encadeada de eventos entendidos como perfis sincrônicos que conformam a estrutura de um campo social a cada ponto significativo de parada no fluxo do tempo [...] representam uma complexa interaçáo entre padróes normativos estabelecidos no curso de regularidades profundas de condicionamento e da experiência social e as aspirações imediatas, ambiçôes ou outros objetivos e lutas conscientes de grupos ou indivíduos no aqui e no agora. (1996, p. XXI e XXII)

4. Todos os trechos citados desse livro foram livremente traduzidos pela autora. 
Drama SOCIAL: NOTAS SOBRE UM TEMA DE VICTOR TuRner $\mid$ I 29

Ao mesmo tempo, é um Turner mais ousado quem nos diz que:

Ao formular a noção de Drama Social, eu tinha em mente a explícita comparação da estrutura temporal de certos tipos de processos sociais com aquelas dos dramas no palco, com seus atos e cenas, cada um com suas qualidades peculiares e todos caminhando para um clímax. (1996, p. XXI)

Turner encontra-se então a um só tempo próximo e distante do pensamento e da influência de Max Gluckman (1911-1975) e dos pressupostos básicos do conjunto de estudos realizados sob sua orientação. Como sabido, no começo de sua carreira, Turner integrava o chamado grupo de Manchester e dos pesquisadores do Rhodes Livingstone Institute (Schumaker, 2004; Engelke, 2004), liderados por Gluckman. A proximidade intelectual existente entre eles pode ser percebida pela forte presença dos temas do conflito, da natureza processual da vida social e do papel integrador do ritual na obra de Gluckman (quem, por sua vez, reconhece expressamente a importância de Bateson, Evans-Pritchard e Fortes para seu pensamento).

Em seu conciso artigo sobre o material etnográfico na antropologia social inglesa, Gluckman (1990 [1959]) destacou o trabalho de Turner, valorizando o dinamismo do estudo dos "casos em processos" empreendido em Cisma e continuidade. Também, em seu conhecido artigo Essay on the ritual of social relations, de 1960, Gluckman (1962, p. 40) fala em uníssono com Turner - "Turner and I think (...)" quando afirma que "os rituais funcionam para encobrir conflitos fundamentais".

Com Gluckman, o lugar central do ritual na estrutura do sistema político já se impusera com todas as letras. Em seu artigo Ritos de rebelião (Gluckman, 1974), inicialmente publicado em 1952, emerge claramente a idéia do sistema social como um campo de tensôes cheio de ambivalências, cooperação e lutas contrastantes. De modo marcante, o tema do ritual emerge do exame da própria história dos zulu, revelando as tensóes sociais críticas dessa sociedade. A idéia de dramatização, por sua vez, já estava formulada ali: os rituais de rebelião dramatizavam as tensóes sociais em toda sua ambivalência.

$\mathrm{Na}$ introdução autobiográfica de Order and rebellion (Gluckman, 1963), a própria conceituação de "ritos de rebeliáo" é vista como sua contribuição central à teoria antropológica. Gluckman destacou que o ritual náo expressava apenas a coesão social ou imprimia "o valor da sociedade e dos sentimentos sociais no povo, como na tese durkheimiana e de Radcliffe-Brown" (Gluckman, op. cit., p. 18). Para ele, o ritual exagerava "conflitos reais de regras sociais, afirmando que a unidade existe apesar dos conflitos". Imediatamente em seguida ele admitiu, entretanto, que a tese de que a unidade social náo se faz apesar dos conflitos mas através dos conflitos, teria sido efetivamente "levada muito adiante por Victor Turner em Cisma e continuidade" (Gluckman, op. cit., p. 18-20, tradução minha).

Ao mesmo tempo, desde cedo, os escritos de Turner (1953) revelam uma inquietação que indica caminhos intelectuais muito pessoais. $\mathrm{Na}$ esteira do interesse do estrutural-funcionalismo pelos rituais, um aspecto dessa inquietação pode ser percebido no nítido realce da funçấo-chave atribuída aos rituais na sociedade $N d e m b u$. Ao simbolizarem valores comuns a todos os $N d e m b u$, os rituais de cura e de aflição geravam um sentido de pertencimento capaz de transcender o permanente estado de tensão interpessoal e conflito político interno às instáveis aldeias. A compreensão, aqui ainda estritamente sociológica, desse lugar central já se abre em Cisma e continuidade (cap. X) para a visão da experiência social como uma experiência de subjetivação realizada através do aprendizado, 
manuseio e atuação dos símbolos. Pois a continuidade da sociedade $N$ dembu (talvez pudéssemos falar, sobretudo, da continuidade de um sentido de pertencimento a um amplo grupo social) repousaria, em última instância, na continuidade de uma "comunidade de sofrimento", cujas tensóes e conflitos se expressariam e, de algum modo, resolver-se-iam ritualmente nos ritos de cura e de afliçáo.

Porém, é preciso acrescentar, como assinalou Geertz (1997), um outro aspecto sobre o qual este texto se detém: a originalidade do uso da metáfora do drama por Turner. A analogia entre a vida social e o drama/teatro há muito tempo já estava disponível nas ciências sociais, tanto na teoria ritual do drama quanto na idéia da vida como um teatro com o desempenho de papéis por atores sociais. Entretanto, como indica Geertz (1997, p. 44), com Turner, a idéia de drama: 1) foi aplicada de modo extensivo e sistemático, não sendo uma metáfora incidental e 2) foi aplicada de forma constitucional e genuinamente dramatúrgica: trata-se de fazer e não de fingir, da possibilidade de transformação da experiência vivida.

Gostaria, neste texto, de sugerir que o referencial propriamente dramatúrgico do uso da metáfora conceitual do drama, desenvolvida especialmente nos capítulos IV e V de Cisma e continuidade, trouxe para a escrita etnográfica de Turner, para além da inovação na análise sociológica estrito senso, o recurso narrativo ao drama como poesis, como atividade plena de mecanismos de simbolização.

Esse procedimento narrativo implícito e eficaz nos transforma, nós leitores de Cisma e continuidade, em espectadores participantes do desenrolar de uma trama que corresponde a um imaginado futuro sociológico, visto como inevitável àquela estrutura social: a fissura da unidade da aldeia Ndembu. Sob a roupagem estrutural-funcionalista, abriga-se uma prefiguração do vindouro Turner das performances sociais. Sua monografia de estréia guarda também algo de sua própria performance como autor/dramaturgo.

\section{Os dramas sociais na aldeia $N d e m b u$}

Cisma e continuidade enfoca a estrutura social dos Ndembu, sobre cuja superfície de regularidades sociais logo emergirão, na forma de dramas, as contradições e os conflitos latentes que lhe conferem dinamismo vital. Essa estrutura é inicialmente apreendida de forma clássica, com muitas genealogias, pesquisa de campo exaustiva, quadros estatísticos e amostragens. Porém, desde o começo da descrição, a vida social Ndembu é apresentada com Pathos, com profunda empatia provocando imediata identificação e compaixão no leitor. Vale retomar rapidamente os argumentos e a caracterização da aldeia feita por Turner. Vejamos:

- A matrilinearidade organiza a base residencial das aldeias $N d e m b u$, garantindo o princípio de sua continuidade ao longo do tempo. Essa almejada continuidade, entretanto, é um objetivo problemático. De um total de 64 aldeias levantadas na mostra quantitativa, apenas uma aldeia perdurava há doze geraçóes. Nos anos 1950, o padráo temporal médio de duração de uma aldeia era de seis gerações. A aldeia Mukanza, base do estudo de caso realizado, então existia há nove geraçôes. $\mathrm{O}$ autor nos informa que a amnésia estrutural começaria tipicamente acima dos ancestrais significativos para os membros vivos da matrilinhagem central da aldeia.

- A combinaçáo do princípio estrutural da matrilinearidade com a regra de casamento virilocal - ou seja, as mulheres deslocam-se para a aldeia do marido quando casam - gera uma grande instabilidade na sociedade Ndembu tanto no casamento dos aldeãos quanto na estrutura residencial de suas aldeias. Operando com 
a matrilinearidade, a virilocalidade impóe a um grupo de irmãos uterinos (siblings) a separação residencial dos parentes com os quais conviveu na infância. Embora esse hipotético grupo de irmãos trace sua ascendência por linha materna, via de regra, ele terá crescido na aldeia de seu pai, ou seja, no seio da matrilinhagem que comanda a rede de parentesco de seu pai. Ao se casarem, os irmãos desse hipotético grupo tendem a levar as esposas para outra aldeia, aquela de sua própria matrilinhagem. Essa mudança residencial faz com que o grupo de siblings masculinos, na primeira oportunidade, tenda a entrar em conflito de lealdade com a nova aldeia como um todo. $\mathrm{O}$ resultado dessa tensão produz grande autonomia da família matricêntrica - o grupo formado por uma mãe e seus filhos - que funcionaria na prática como a unidade social básica. Nesse quadro, o grupo de siblings uterinos em idade adulta tende a constituir a primeira e mais provável ameaça à manutenção da integridade de uma aldeia, formando, nas palavras de Turner, a "primeira unidade de fissão".

Por sua vez, as irmãs desse mesmo grupo hipotético - que, quando casam, deslocam-se para a aldeia do marido - manterão, mesmo depois de casadas, um forte laço com seus irmãos. Com seus filhos, elas formam uma base potencial importante para os grupos de apoio político a um homem/irmão sênior e aspirante à liderança aldeã. Não é de se estranhar que os divórcios sejam freqüentes.

- Essas fortes tendências à instabilidade são contrabalançadas por alguns mecanismos. Se um casamento virilocal perdura, com a criação dos filhos na aldeia paterna, há uma tendência à fusão dos parentes da mãe e do pai. Cria-se, nesse caso, uma geração genealógica que atravessa a família matricêntrica, unindo primos cruzados e primos paralelos. A ligação entre as duas linhas de ascendência é então assegurada pelos casamentos entre primos cruzados ou pelos casamentos entre geraçôes alternadas.
Assim, na sociedade Ndembu combinamse, em grande tensão, o ideal de construir grandes e duradouras aldeias e a mobilidade real e freqüente de seus membros. Na prática, cada grupo de descendentes maternos encontra-se espalhado em diferentes vizinhanças, todas de composição heterogênea, e há um contínuo fluxo de visitas entre os parentes matrilineares residentes em aldeias diversas, gerando o que Turner caracteriza como um individualismo característico dos Ndembu.

Porém, a efetiva compreensão desses princípios estruturais contraditórios e em permanente operação passa pelo apelo, desde o prefácio à primeira edição de 1957 (p. XXVII), à compaixão e à empatia do leitor por aqueles homens e mulheres concretos. Todo homem $N d e m b u$ vê-se dividido num insolúvel conflito de lealdade entre sua esposa (como maridos, os homens querem manter suas mulheres e filhos) e suas irmãs (como irmáos, querem recobrar para si a lealdade de suas irmãs e sobrinhos). Conflito semelhante ocorre com as mulheres, sempre divididas entre os papéis de esposas e irmãs. Ora, para nós leitores, nos capítulos IV e V, esses homens e mulheres logo se tornarão pessoas concretas, ou melhor, personagens muito particulares.

Nesse tipo de estrutura social, Turner constata que os distúrbios a ele relatados pelos Ndembu e/ou por ele diretamente presenciados, não só manifestavam esses conflitos latentes como obedeciam a um padrão, constituindo, em suas palavras "uma forma orgânica em que uma etapa evolui da anterior", ou seja, um drama. Com essa idéia de drama, Turner opera também com uma idéia muito precisa de atores:

as diferentes personalidades ocupam posiçóes sociais que devem inevitavelmente entrar em conflito e cada ocupante de uma posição deve apresentar seu caso em termos de normas aceitas por todos (1996, p. 94). 
$\mathrm{Na}$ seqüência desse raciocínio, acompanhamos entáo a chegada do autor à formulaçãochave do livro:

A situação em uma aldeia Ndembu é muito próxima àquela encontrada no drama grego no qual assistimos à impotência do indivíduo humano diante do destino: mas nesse caso o destino são as necessidades do processo social. (Turner, 1996, p. 94)

Turner analisou sete dramas sociais. Os dois primeiros foram reconstituídos a partir de narrativas diversas dos aldeãos. Eles introduzem a situaçáo política da aldeia tal como encontrada em 1950 por Turner (Ver diagrama abaixo).

A aldeia Mukanza encontrava-se entáo sob a chefia de Mukanza Kabinda (F8), da sub-linhagem Nyachitang'a, cuja esposa sênior era Nyamukola (H10), por sua vez, pertencente à geração alternada e membro da sub-linhagem Malabu. Os dois primeiros dramas introduzem em um campo de ação o posicionamento dos diversos personagens/aldeãos na estrutura das relaçóes sociais da aldeia. A ação se desdobra no contexto da tensão e do confronto latentes em torno das expectativas e ambiçôes masculinas pela chefia da aldeia.

O Capítulo V, que contém os três primeiros dramas diretamente vivenciados por Turner em sua primeira permanência em campo, é especialmente esclarecedor. $\mathrm{O}$ primeiro deles é de setembro de 1951, e o investigador percebe sua presença no cenário aldeão como um "fator de ação". A análise desses três dramas revela com limpidez o "sistema em operação na vida cotidiana" e, com isso, o vívido perfil humano dos principais personagens. Vejamos mais de perto, no diagrama abaixo.

No drama III, Kasonda (G15), o assistente de Turner, alfaiate e um dos adultos sênior da principal sub-linhagem da aldeia, Nyachitang'a, cujo tio materno Mukanza Kabinda (F8) é o chefe da aldeia, é o motivo do início da açáo. Estando a serviço do antropólogo, Kasonda náo teria podido comparecer a um ritual importante ocorrido na aldeia Mukanza no início de 1951. Algum tempo depois, ele é acusado de ter enfeitiçado o ir-

\section{Diagrama daS DUAS PRINCIPAIS SUB-LINHAGENS DA ALDEIA MUKaNZA ${ }^{5}$}

D1 = linhagem Nyachitang' a

D2 = linhagem Malabu

(com a marcação dos principais personagens)

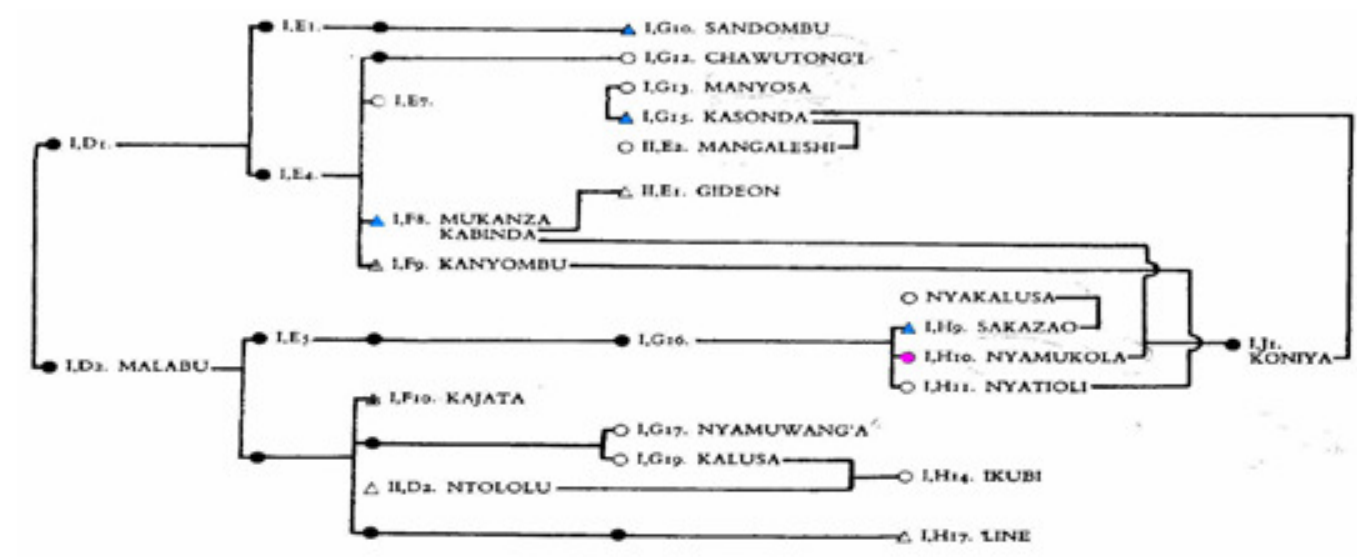

5. Esse diagrama representa a geração J apenas por Koniya (J1) (por sinal esposa de Kasonda, G15). Não mostra a sua irmã, J2, Zuliyana, também filha do casal Mukanza Kabinda (F8) e Nyamukola (H1O), esposa de Sandombu (G10) e pivô do drama $V$. 
Drama Social: NOtAS SOBRE UM TEMA DE Victor Turner | I33

mão de Mukanza Kabinda, seu outro tio-materno Kanyombu (F9), que havia morrido, e da malária, segundo Turner, que assola o próprio chefe Mukanza Kabinda (F8) e também Sakazao (H9). Este último é de uma geração abaixo de Kasonda (G15) e integra a outra sub-linhagem formadora da aldeia, Malabu.

Entre as principais acusadoras está a esposa do chefe Mukanza, Nyamukola (H10), da sub-linhagem Malabu. Nesse drama, somos apresentados à sensível e sutil inteligência diplomática da retórica defensiva de Kasonda que reverte a situação a seu favor.

O drama IV se inicia com a morte por malária de Ikubi (H14), uma jovem da linhagem Malabu, e agora a acusação de enfeitiçamento recai sobre Nyamuwang'a (G17), mulher viúva e sênior da mesma geração de Kasonda, tia materna de Ikubi e integrante da sub-linhagem Malabu. Sakazao (G15, sub-linhagem Malabu) pede para Nyamuwang'a se retirar para outra aldeia, não por ser feiticeira, mas por sua tendência de sempre criar confusão. E lá se vai Nyamuwang'a, levando sua filha, sendo ambas logo depois acolhidas de volta por Sandombu (G10).

O leitor de Cisma e Continuidade já havia sido apresentado a Sandombu, homem sênior e estéril da mesma geração de Kasonda e da mesma sub-linhagem dominante Nyachitang'a desde o drama I. No drama II, a conduta de Sandombu já revelara sua inveja e ambição pela chefia. Na ocasiáo relatada, ele tinha sido expulso da aldeia, embora logo depois tenha sido perdoado e aceito de volta.

$\mathrm{O}$ drama $\mathrm{V}$ começa com as reclamaçôes das duas mulheres de Sandombu (Zuliyana e Katiki) que querem um tecido bonito para fazer um vestido e mais recursos oriundos das colheitas que realizam. Zuliyana acusa seu esposo Sambombu de ambicionar a chefia da aldeia (que pertence a seu pai Mukanza Kabinda) e foge para a casa dos pais. Na seqüência, Sandombu acusa Nyamukola, a mãe de Zuliyana e esposa do chefe Mukanza Kabinda, de ter passado um feitiço para a filha para ela, por sua vez, enfeitiçá-lo, a ele Sandombu. Sandombu mantém a acusação em praça pública, mas, mesmo assim, Zuliyana volta para casa com o marido. Sakazao (sub-linhagem Malabu) defende Sandombu, dizendo que este apenas estava bêbado e que, como retratação, deveria simplesmente pagar uma multa à sogra ofendida. Enquanto isso ocorre, Sandombu enfrenta uma antiga disputa com o chefe de outra aldeia da vizinhança por xingamento, e todos os aldeãos de Mukan$z a$ lhe dáo apoio, exceto o casal chefe, Mukanza Kabinda e Nyamukola. Para alegria de toda a aldeia Mukanza, Sandombu ganha esse caso paralelo e sua aldeia decide entáo que ele deve apenas pagar uma multa de dez shillings para sua sogra Nyamukola.

Turner teoriza então:

um sistema social está em movimento dinâmico através do tempo e do espaço, de algum modo análogo a um sistema orgânico no sentido em que ele exibe crescimento e decadência, de fato o processo de metabolismo (1996, p. 161).

Porém, a essa interpretação caracteristicamente funcionalista sobrepóem-se dois outros aspectos oriundos da analogia proposta entre o processo social e a idéia dramatúrgica, a saber:

1) No encadeamento das seqüências de açôes, o drama social revela aquilo que ocorreria imperceptivelmente no fluxo cotidiano da aldeia: o realinhamento das relaçóes sociais em pontos críticos de maturação ou declínios estruturais. Esses pontos críticos da estrutura social em movimento dinâmico conformam a dimensão de destino inexorável que Turner atribui aos processos sociais que analisa.

2) Ao mesmo tempo, esses desdobramentos de açôes podem ser vistos como uma prova de força entre interesses conflitantes de pessoas e 
grupos que tentam manipular, cada qual em seu próprio benefício, a rede de relaçôes sociais estruturais e circunstanciais. Esses processos sociais revelariam então outra dimensão embutida na metáfora dramatúrgica, aquela do embate entre os homens que abre um campo de alternativas possiveis para a ação.

Esses três dramas alinhados revelam claramente que a unidade residencial da aldeia Mukanza repousava no laço entre as duas sublinhagens principais Nyachitang'a e Malabu, expressa no casamento do chefe Mukanza Kabinda com Nyamukola. O risco de rompimento desse laço é o futuro que pressiona inexoravelmente o presente.

É preciso notar que, à certa altura dos relatos, Turner entra na cena dramática por ele montada. Como o diretor de um filme de Carlos Saura (Doces momentos do passado), que perde a distância analítica da direção e passa a atuar na cena como mais um de seus personagens, o autor-dramaturgo passa a analisar possíveis desdobramentos futuros "quando Mukanza Kabinda morrer" (1996, p. 165). Turner indaga-se sobre um futuro, tido por ele como inevitável, quando, com a morte de seu chefe, a aldeia Mukanza inevitavelmente fissionaria.

Essa idéia de uma necessária fissura da aldeia corresponde ao peso do destino sobre os atos humanos e, com essa expectativa de destino vindouro, Turner cria grande tensão dramática envolvendo intensamente o leitor em sua narrativa. Nesse futuro vislumbrado como destino, a aldeia Mukanza, nos diz o autor, clivar-se-ia em duas - com Kasonda (sub-linhagem Malabu) e Sandombu (sub-linhagem Nyachitang'a) fundando cada qual sua própria aldeia, e com Sakazao (sub-linhagem Malabu) assumindo a chefia da aldeia Mukanza. Vale informar que nada disso, como comenta Turner no Prefácio à edição de 1968 (p. XXIII), veio a ocorrer. Mukanza Kabinda foi um chefe longevo e morreu em 1967. Foi sucedido, sem maiores conflitos, por Kasonda.
A aldeia Mukanza manteve sua integridade por mais uma geração.

Essa seqüência dos três dramas apresentados no capítulo $\mathrm{V}$ desemboca diretamente no magnífico capítulo $\mathrm{X}$, no qual Turner analisa - "sociologicamente", ele enfatiza, e não "simbolicamente", tarefa que ele nos avisa ter deixado para um outro momento - um culto de aflição. Trata-se do ritual Nkula (esquecimento do ancestral) que teve como foco justamente Nyamukola, a esposa de Mukanza Kabinda, pertencente à sub-linhagem Malabu e submetida à grande tensão pessoal no decorrer dos dramas analisados. No processo de nominação desenvolvido no rito, descobre-se que o espírito que a afligia era Nyamukang'a, a ancestral de sua linhagem Malabu. O principal organizador desse ritual foi Sandombu (sub-linhagem Nyachitang'a) e a principal mulher de Sakazao (sênior da linhagem Malabu). Através de uma identificação pelo sofrimento, os laços de solidariedade que mantêm a aliança das duas sublinhagens e, portanto, a própria continuidade da aldeia Mukanza, se refazem.

Embora a noção de drama social focalize a ação social, vale ressaltar o fato aparentemente óbvio de que os dramas sociais analisados são necessariamente narrativas sobre açôes, ou seja, as ações propriamente ditas foram objeto de uma transposição ficcional, e existem na forma de narraçóes idealizadas e ordenadas por nosso autor. Do ponto de vista nativo, o processo de acusação interno à aldeia, que sempre se segue à irrupção da crise inauguradora de um drama qualquer, é ele mesmo uma análise e autoanálise da conduta dos atores/personagens. $\mathrm{O}$ autor/antropólogo organiza essas narrativas e ações na sua própria narrativa de um drama revelador das razóes estruturais implícitas aos conflitos explicitados pelas acusaçóes, defesas e contra-acusaçôes que movimentam a trama de ações. Temos assim o resultado tão almejado e aplaudido por Gluckman - a descrição de um 
processo social em movimento, um modelo dinâmico de sociedade em que ação relacional, reconstituída e apresentada de forma dramática, é interpretada dentro dos princípios da estrutura social.

Entretanto, indo além dos paradigmas do funcionalismo, vale aprofundar o referencial dramatúrgico da idéia de drama. Por esse viés, o drama social é também - além da "principal unidade de descrição e análise no estudo do processo social" (Turner, 1996, p. XXV), com as suas quatro fases características (quebra de uma regra ou valor; crise; ação reparadora; re-integração ou reconhecimento do cisma) um curso de tempo ativo de experimentaçáo subjetiva, afetiva e cognitiva, dos princípios estruturais pelos personagens/atores sociais. Seu desenrolar não apenas revela os focos de tensão da estrutura social, mas constitui também um lugar de possível reflexão, análise e auto-análise e de transformação conceitual e interior da pessoa Ndembu em seus relacionamentos.

O ambicioso Sandombu, afinal, chorou sinceramente, lá no drama II, quando foi acusado de enfeitiçar Nyamuwhala (irmã de Mukanza Kabinda e de Kahali Chandenda que já tinha morrido). Ao retornar para a aldeia Mukanza um ano depois, Sandombu ofertou uma cabra para o chefe Mukanza Kabinda e promoveu um ritual para a ancestral comum (Turner, 1996, p. 129).

O mesmo Sandombu riu deliciosamente quando acusado de xingamento pelo chefe da aldeia vizinha no drama $\mathrm{V}$, até perceber que se tratava de uma acusação para ser levada a sério. Então se defendeu e, ao fazê-lo, tornou efetivamente sua a aldeia Mukanza, ganhando com isso o apoio de todos os aldeãos (menos o do casal chefe). Logo em seguida, ele promoveu o rito Nkula (Capítulo X) para Nyamukola, sua sogra, pertencente à sub-linhagem Malabu.

Sandombu é assim muito mais do que o invejoso, frustrado e esquentado homem sênior da linhagem Nyachitang'a que almeja à chefia da aldeia a qualquer custo. Sandombu é, como nos sugere a epígrafe de William Blake no livro, um homem particular, aquele "lugar único onde as formas gerais ganham vitalidade".

Turner opera com chaves conceituais precisas em seu criativo uso da analogia do drama para a compreensão da vida social. $\mathrm{O}$ referencial para a transposiçáo ficcional efetuada pela narrativa do drama social é a situação do desenrolar das açóes dentro de uma moldura temporal e espacial nítida. Como nos diz Susan Langer (2003, p. 429), o drama é como a ação, produzindo a ilusão do ato. É causal, pois provém de um passado e cria uma experiência total e iminente. Estabelece um presente que contém a origem de um futuro ou um destino necessário. $\mathrm{O}$ dramático, na visão dessa autora, é especificamente esse sentido do presente que, vindo de um passado, é preenchido com a qualidade de seu próprio futuro. Esse futuro embutido no presente organiza e unifica o contínuo da ação. No drama, nos diz Langer (2003), o futuro acontece diante de nossos olhos. Esse sentido de destino presente na ação dramática fornece o sentido de totalidade e de organicidade ao desenrolar das ações narradas por Turner.

O drama é uma história que está vindo: Quando a aldeia Mukanza fissionará? A pergunta sobre esse futuro insinuado por Turner confere ritmo dramático às narrativas analisadas. De tal modo que nós, leitores de Cisma e continuidade, vemo-nos imperceptivelmente colocados no lugar do espectador teatral, cheios de empatia e munidos de suficiente distância psíquica para nos entregarmos à ilusão dramática. Foi com essa ilusão - no sentido de uma construção de natureza ficcional (Langer, 2003) - que Victor Turner elaborou a parte mais contemporânea de seu estudo.

Turner narrou o desenrolar de açốes como uma engrenagem natural de comportamentos, 
em que "a significação de cada pequeno ato é aumentada, porque mesmo o menor ato está orientado para o futuro" (Langer, 2003, p. 319). Através de pessoas - Kazonda, Sakazao, Sandom$b u$ - que, tornadas atores, enfrentam-se com o destino de sua estrutura social, nós leitores, experimentamos a tensão da pergunta mantida em suspenso durante todo tempo narrativo: quando a aldeia Mukanza fracionará?

Cisma e Continuidade inscreve-se na tradição disciplinar hoje considerada clássica. Porém, como procurei demonstrar, nessa primeira fase de sua trajetória intelectual, o brilho de Turner não resulta apenas do esmero com que obteve os dados analisados em sua monografia de estréia, como sugeriu Kuper (1973). Nem apenas, como saudou à época Gluckman (1963), da percepção de uma ordem que se cria através de processos de conflito. Tal e qual um dramaturgo, com os dramas sociais que movimentam e pontuam a narrativa de Cisma e Continuidade, Victor Turner nos apresenta poemas em forma de ação.

\section{Social dramas: notes on a Victor Turner's} theme

abstract This paper analyzes the notion of social drama elaborated by Victor Turner in Schism and continuity in an African society, following on Clifford Geertz' view of this conceptual metaphor's dramaturgical basis. The text examines the development of fictional devices in Turner's ethnography in the context of a structural-functionalist approach. With the social dramas' narratives, Turner transfor$\mathrm{ms}$ the reader in a theatrical spectator. Following the development of the main characters' actions, we find ourselves watching the unfolding of a plot that evolves towards an imagined sociological future, seen as inevitable: the Ndembu village's fission.

keywords Victor Turner. Social drama. Conceptual metaphor. Dramatic illusion. Ethnography.

\section{Referências bibliográficas}

CLIFFORD, James. Sobre a alegoria etnográfica. In: GONÇALVES, J. R. (Org.). A experiência etnográfica: antropologia e literatura no século XX. Rio de Janeiro: EdUFRJ, 1998, p. 63-99.

DAMATTA, Roberto. Individualidade e liminaridade: consideraçôes sobre os ritos de passagem e a modernidade. Mana. Estudos de Antropologia Social, v. 6, n. 1, p. 7-29, 2000.

Carnavais, Malandros e heróis. Rio de Janeiro: Zahar Editor, 1979. 350 p.

DAWSEY, John. O teatro em Aparecida: a Santa e o Lobisomem. Mana. Estudos de Antropologia Social, v. 12, n. 1, p. 135-149, 2006.

Victor Turner e a antropologia da experiência. Cadernos de Campo, Sáo Paulo, n. 13, ano 14, p. 163 $176,2005$.

DE BOECK, Filip; DEVISCH, Rene. Ndembu, Luunda and Yaka divination compared: from representation and social engeneering to embodiment and worldmaking. Journal des religions africaines, v. XXIV, n. 2, p. 1-23, 1994.

DEFLEM, Mathieu. Ritual, anti-structure, and religion: a discussion of Victor Turner's Processual Symbolic Analysis. Journal for the Scientific Study of Religion, v. 30, n. 1, p. 1-25, 1991.

ENGELKE, Mathew. The endless conversation: Fieldwork, writing, and the marriage of Victor and Edith Turner". In: HANDLER, Richard (Org.) Significant Others: interpersonal and professional commitments in anthropology. Winsconsin: The University of Wisconsin Press, 2004, p. 6-49.

GEERTZ, Clifford. O saber local. Petrópolis: Vozes, 1997. 244p.

GLUCKMAN, Max. Les rites de passage. In: GLUCKMAN, Max (Org.) Essays on the ritual of social relations. Manchester: Manchester University Press, 1962 [1960]. p. 1-52.

. Order and rebellion in tribal Africa. London: Cohen \& West, 1963. 273p.

Ritos de rebelião. Cadernos de Antropologia, Brasília, n. 4, 1974. 42p.

O material etnográfico na antropologia social inglesa. In: ZALUAR, Alba (Org.) Desvendando máscaras sociais. Rio de Janeiro: Francisco Alves, 1990 [1959], p. 64-76.

GONÇALVES, José Reginaldo Santos. Apresentação. In: CLIFFORD, J. A experiência etnográfica: antropologia e literatura no século XX. Rio de Janeiro: EdUFRJ, 1998, p. 7-16. 
Drama SOCial: NOTAS SOBRE UM TEMA DE Victor Turner | I 37

KUPER, Adam. Antropólogos e antropologia. Rio de Janeiro: Francisco Alves, 1973. 228 p.

LANGER, Susanne. Sentimento e forma. São Paulo: Perspectiva, 2003 [1953]. $439 \mathrm{p}$.

LENCLUD, Gérard. Victor Witter Turner. In: BONTE, Pierre; IZARD, Michel (Orgs.). Dictionnaire de l'Ethnologie et de l'anthropologie. Paris: Presses Universitaires de France, 1991, p. 721-722.

LEOLPOLDI, José Sávio. Escola de samba, ritual e sociedade. Petrópolis: Vozes, 1978. 146 p.

LÉVI-STRAUSS, Claude. O Pensamento Selvagem. São Paulo: Ed. Nacional, 1976. 331 p.

MAGGIE, Yvonne. Guerra de Orixá: um estudo de ritual e conflito. Rio de Janeiro: Zahar Editor, 2001. 181 p.

PEIRANO, Mariza. As árvores Ndembu, uma re-análise. Anuário Antropológico de 1990, Rio de Janeiro: Tempo Brasileiro, p. 9-64, 1993.

SCHUMAKER, Lyn. The director as significant other. Max Gluckman and Team Fieldwork at the Rhodes-Livingstone Institute. In: HANDLER, Richard (Org.). Significant others: interpersonal and professional commitments in anthropology. Winsconsin: The University of Wisconsin Press, 2004, p. 91-130.

SILVA, Rubens Alves. Entre 'artes' e 'ciências': as noções de performance e drama no campo das ciências sociais. Horizontes antropológicos, Porto Alegre, ano 11, n. 24, p. 35-65, 2005.

TURNER, Victor. Lunda rites and ceremonies. The occasional papers of the Rhodes -Livingstone Museum, University of Zambia by Manchester University Press, n. 10, p. 335-388, 1953.

. The drums of affliction: a study of religious processes among the Ndembu of Zambia. Oxford: Oxford University Press, 1968. 326 p.

O processo ritual: estrutura e anti-estrutura. Petrópolis: Vozes, 1974 [1969]. 248 p.
From ritual to theatre: the human seriousness of play. New York: PAJ Publications, 1982. 127 p. The anthropology of performance. New York: PAJ Publications, 1987. 185 p.

Schism and continuity in an African society. Manchester: Manchester University Press, 1996 [1957]. $348 \mathrm{p}$.

Floresta dos simbolos: aspectos do ritual Ndembu. Niterói: EdUFF, 2005 [1967]. 488 p.

TURNER, Victor; BRUNER, Edward M. The anthropology of experience. Urbana and Chicago: University of Illinois Press, 1986. 391p.

VAN GENNEP, Arnold. The rites of passage. Chicago: Chicago University Press, 1960 [1909]. 198 p.

VOGEL, A.; MELLO, M.A.S.; BARROS, J. F. P. Galinha d'Angola: iniciaçâa e identidade na cultura brasileira. Rio de Janeiro: Pallas, 1998. 204 p.

WEBER, Donald. From limen to border: a meditation on the legacy of Victor Turner. American Cultural Studies. American Quarterly, American Studies Association, v. 47, n. 3, p. 525-536, 1995.

\section{Notas}

Versōes iniciais deste trabalho foram apresentadas na mesa redonda "Do ritual à performance", na 25a Reunião Brasileira de Antropologia, em Goiânia, em junho de 2006, e no V Laboratório de Análise Simbólica, PPGSA/IFCS/UFRJ, em agosto de 2006. Agradeço as sugestôes e críticas que recebi dos participantes destes dois eventos.

\section{autor Maria Laura Viveiros de Castro Cavalcanti}

Professora do Departamento de Antropologia Cultural/IFCS-UFRJ

Doutora em Antropologia Social/IFCS-UFRJ

Pós-Doutora/Columbia University

Recebido em 14/05/2007

Aceito para publicação em 29/11/2007 